\title{
Design of Cooling and Heating Tool Using Thermoelectric Peltier Based on Arduino Uno
}

\author{
M. Kevin Rambang Alam ${ }^{1)}$, Helmi Fitriawan ${ }^{2 *}$, F.X Arinto Setyawan ${ }^{3)}$, and Umi Murdika ${ }^{4)}$ \\ ${ }^{1,2,3,4)}$ Department of Electrical Engineering, University of Lampung, Bandar Lampung, Lampung, Indonesia \\ Corresponding Email: ${ }^{*}$ helmy.fitriawan@eng.unila.ac.id
}

\begin{abstract}
Cooler is an electronic device used to cool food and drinks. The current cooling system still uses refrigerants that can damage the ozone layer. The thermoelectric based cooling system can be used as an alternative since it produces sufficient temperature difference on both sides by considering its advantages that is more environmentally friendly. This research is aimed to design and built a cooling and heating system using a thermoelectric Peltier TEC 12715 based on microcontroller Arduino uno. This system uses the Peltier thermoelectric effects as coolant and warmer because it produces temperature difference on both sides. Based on this research, in the no load condition the system can produce a cold temperature of $21,3{ }^{\circ} \mathrm{C}$ and a hot temperature of $80,2{ }^{\circ} \mathrm{C}$ in the $40^{\text {th }}$ minute of use. When given a load of $300 \mathrm{ml}$ and $220 \mathrm{ml}$ drink bottles, the system can produce a cold temperature of $22,2^{\circ} \mathrm{C}$ and a hot temperature of $70,7^{\circ} \mathrm{C}$ in the $40^{\text {th }}$ minute of use. The TEC 12715 Peltier component used in this research produces the optimal temperature if a voltage of 12 volts and a current of 15 amperes are applied to each Peltier component. The designed system is able to operate repeatedly, properly, and continuously since it is directly connected to alternative current power which is common in households.
\end{abstract}

Keywords: Thermoelectric, Peltier, Arduino uno, cooler, heater

\section{INTRODUCTION}

Along with technological developments that have been achieved by humans, it is getting easier for needs including household appliances. One of the common household appliances are coolers. The current cooling system still uses refrigerants that can damage the ozone layer [1]-[3]. One of the efforts that can be done is to replace the refrigerant with another material which basically does not cause the same negative effects as the refrigerant material. The refrigerant can be replaced with a thermoelectric which has the characteristic of being able to cool it without producing the global warming effect that previously could be caused by refrigerants.

Basically, if two different types of metal have a relationship between electrical energy and heat energy, it can be said to be thermoelectric. Peltier is a thermoelectric component whose use can replace refrigerants because it does not have a damaging effect on the environment by utilizing the Peltier or thermoelectric effect. The Peltier effect occurs whenever the current passes through a series of two different conductors depending on the current direction, the junction of the two conductors absorbs or releases heat [4].

The phenomenon of the peltier effect can be observed if a closed circuit consisting of a connection of two metal materials is subjected to a direct electric current, so at this connection one side will release heat while the other side will absorb heat [5]. The Peltier effect phenomenon occurs when two conductors arranged side by side are connected by electricity, electrons flow from the less electronically bound conductor to the more electronically bound conductor [6]. This can occur because of the Fermi difference between the conductors.

Fermi is the highest level of energy an electron can occupy. When the fermi level between two conductors is combined, the conductor that has a higher level to the conductor that has a lower level will flow electrons which will cause a change in electrostatic potential [7]. Current passing through the junction in the forward or backward direction will cause a temperature difference in temperature. The temperature of the hot junction is kept low by eliminating the temperature difference and also the cold junction temperature [8].

Peltier coefficient which can adjust the Peltier effect is the Seebeck coefficient of the semiconductor material and the absolute temperature. The cooling effect can be related to the Peltier coefficient as the current flowing through the $\mathrm{N}$-type material to the P-type material and the heat effect is obtained if the current passes through the Ptype material to the $\mathrm{N}$-type material. The temperature of the hot and cold sides can be reversed if the direction of the current flowing is also reversed. Peltier coefficient values and current flow in semiconductor materials will affect the amount of heat absorbed in the cold section and dissipated in the hot section.

Thermoelectric modules are designed and made from many semiconductor connections joined together to form a thermoelectric device or module. Thermocouples will form when the semiconductors in the module are connected to one another. The way the thermoelectric works is by converting heat energy into electrical energy directly and it can work the other way around. If the current flows through a thermoelectric material, the heat around the environment will be absorbed. Based on this, it can be seen that there is no need for a refrigeration compressor which is commonly used in conventional 
cooling machines that have existed before. The way the thermoelectric works can be illustrated in Figure 1.

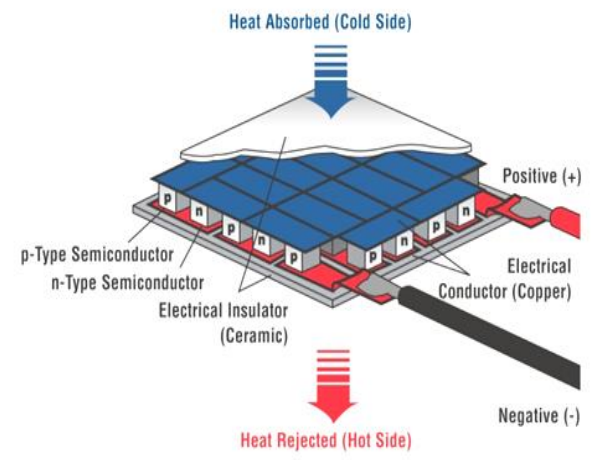

Figure 1. Peltier System

The thermoelectric module in its use must be supported by the heat dissipation generated on the hot side. If the ambient temperature is the same as the hot temperature, the resulting cold temperature will be lower [9]. The heat pumping action is due to the function of many electrons passing through the P-N Junction [10].

\section{Methodology}

\section{A. System Architecture}

In this research, the design and manufacture of cooling and heating system that can work in accordance with the block diagram is carried out as shown in Figure 2.

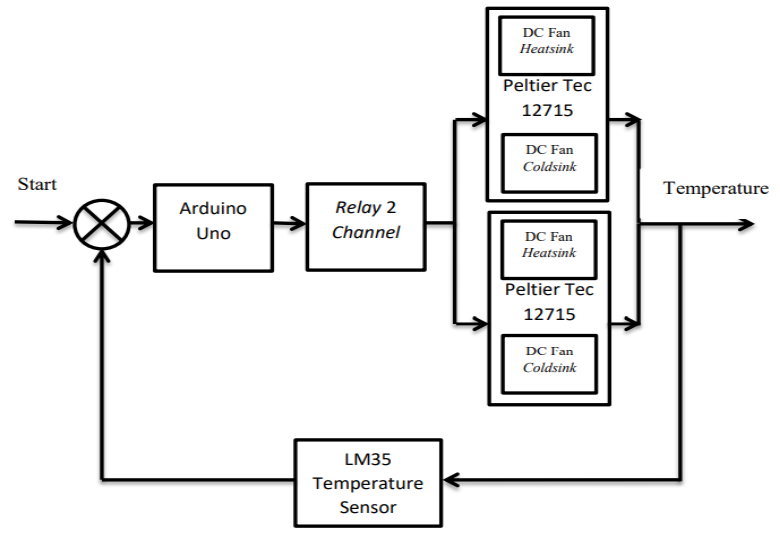

Figure 2. System Block Diagram

Based on Figure 2, it can be seen that the system used is an open loop because system performance is not affected by feedback. Figure 2 shows how the designed tool system works, namely when the Arduino Uno microcontroller is given an input setting point which will set the Peltier on or off on the box using the IR remote. The remote signal will be received by a receiver connected to Arduino then the relay will be active which causes the activation of the Peltier and the fans. The cold part is connected to the cold sink so that the distribution of cold temperatures is more optimal. The hot part is connected to a heatsink to disperse and dissipate heat. The wasted heat is collected into a part of the box which functions as a heater. The LM35 sensor is used to detect cold and hot temperatures generated by the two-sided
Peltier element. The sensor is also used as a temperature feedback that is generated with a reference temperature. Arduino has a function to adjust the state of the on or off relay that has been connected to the power supply. The LCD will display the temperature measured by the sensor so that it can be known and analyzed by the user.

This research uses Arduino Uno with ATmega 328 microcontroller. The way of communication between Arduino Uno and the ATmega 328 microcontroller with a personal computer is by USB. The initial stage for testing the Arduino Uno used is to determine whether the Arduino Uno with the ATmega 328 microcontroller can be connected to a personal computer or not. Testing by checking whether the Arduino used is connected to a personal computer is through software made for the creation of the Arduino program, namely the Arduino IDE (Integrated Development Environment) application. As for the home screen display of the Arduino IDE (integrated development environment) application is shown in Figure 3.

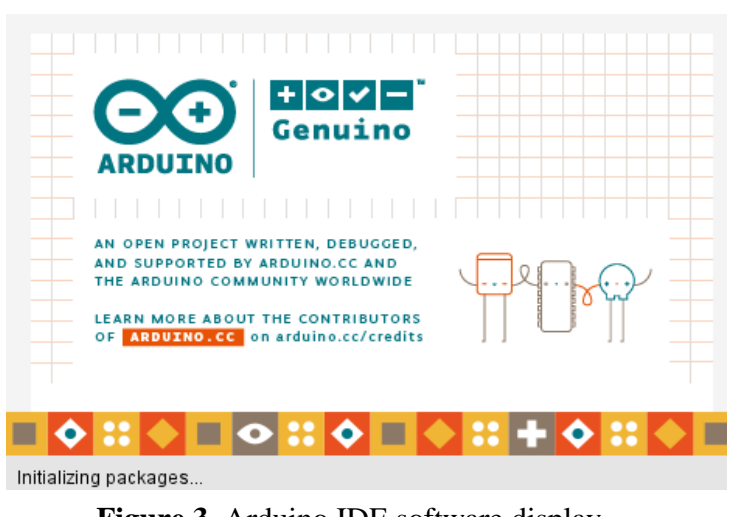

Figure 3. Arduino IDE software display

Arduino uno's function in the design of this system is to control the performance of several important components because the source code that has been programmed on the Arduino uno can adjust the performance of the LCD, sensors, relays, IR remotes, and IR receivers.

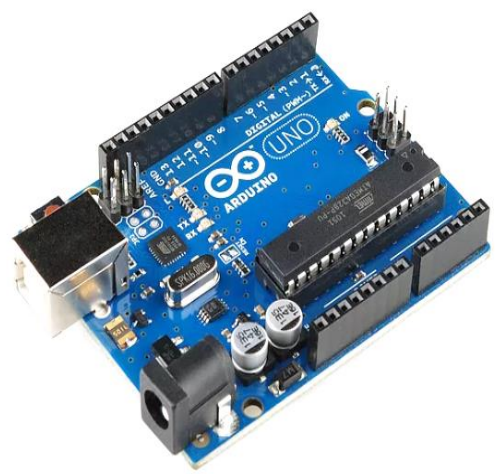

Figure 4. Arduino Uno ATmega 328

The Arduino Uno shown in figure 4 can also adjust when the temperature is below $17^{\circ} \mathrm{C}$ Peltier and the dc fan will turn off, while when the temperature is above 20 ${ }^{\circ} \mathrm{C}$ Peltier and the fan will turn on again. The temperature for the deactivated Arduino is set at $17{ }^{\circ} \mathrm{C}$ caused by the heat generated when the temperature of the cooling 
section reaches $17{ }^{\circ} \mathrm{C}$, then the heating section will produce a temperature of $\pm 80^{\circ} \mathrm{C}$. This is applied as a protection system so that the heating section will not overheat when the tool is continuously activated and to reduce the impact of damage to the tool material if the heating section produces a temperature that is too hot. The Arduino uno also acts as a connector and power provider of LM35 sensors, 16x2 LCD and 2 channel relays

The complete specifications of the Arduino Uno components used in this study can be written more fully in Table 1.

Table 1. Arduino uno specifications used [11]

\begin{tabular}{cc}
\hline Specification & Information \\
\hline Microcontroller & ATmega 328 \\
\hline Operating Voltage & $5 \mathrm{~V}$ \\
\hline $\begin{array}{c}\text { Input Voltage } \\
\text { (recommendation) }\end{array}$ & $7-12 \mathrm{~V}$ \\
\hline $\begin{array}{c}\text { Input Voltage (final } \\
\text { limit) }\end{array}$ & $6-20 \mathrm{~V}$ \\
\hline $\begin{array}{c}\text { Digital I / O Pin } \\
\text { Analog Input Pin }\end{array}$ & 6 pins as PWM \\
\hline $\begin{array}{c}\text { DC current per I / O } \\
\text { pin }\end{array}$ & $40 \mathrm{~mA}$ \\
\hline $\begin{array}{c}\text { DC current for the 3.3 } \\
\text { V pin }\end{array}$ & 50 mA \\
\hline Flash Memory & $\begin{array}{c}\text { 32 KB (ATmega 328) } \\
0.5 \mathrm{~KB} \text { for bootloader }\end{array}$ \\
\hline SRAM & $2 \mathrm{~KB}$ (ATmega 328) \\
\hline EEPROM & $1 \mathrm{~KB}$ (ATmega 328) \\
\hline Clock Speed & $16 \mathrm{MHz}$ \\
\hline
\end{tabular}

Peltier components have several types of Peltier that are different from one another. Each type of Peltier has different voltage and current specifications to work optimally. This research uses TEC 12715 Peltier component with a voltage specification of 12 volts and a DC current of 15 amperes to operate optimally. Figure 5 shows the Peltier component used in this study.

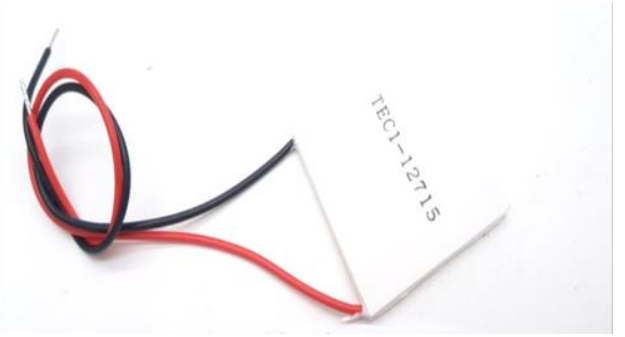

Figure 5. Peltier TEC 12715

Based on Figure 5, it is known that the Peltier component has two wires, the red wire is connected to the positive pole and the black wire is connected to the negative pole. The Peltier component also has hot and cold sides. The cold side of the Peltier is generally marked by the writing of the specification of the type of Peltier used, while the hot side is the side that does not have the specification of the Peltier. Peltier must use thermal grease and heatsink to avoid damage to components.

Peltier testing is carried out by providing a voltage of 12 volts and a DC current of 15 amperes from the power supply so that the Peltier used in this study will be active and operate as intended so that there is no component damage in this study. The complete specifications of the Peltier components used in this study can be written more fully in Table 2 .

Table 2. Peltier specifications used [12]

\begin{tabular}{cccc}
\hline No & Information & Symbol & $\mathrm{K}$ \\
\hline 1 & $\begin{array}{c}\text { Maximum Operating } \\
\text { Temperature }\end{array}$ & $\mathrm{T}$ & $\leq 90{ }^{\circ} \mathrm{C}$ \\
\hline 2 & $\begin{array}{c}\text { Maximum Temperature } \\
\text { Difference }\end{array}$ & $\Delta \mathrm{Tmax}$ & $70^{\circ} \mathrm{C}$ \\
\hline 3 & $\begin{array}{c}\text { Maximum Input } \\
\text { Voltage }\end{array}$ & $\mathrm{Vmax}$ & $15.4 \mathrm{~V}$ \\
\hline 4 & Maximum Current & $\mathrm{Imax}$ & $15.0 \mathrm{~A}$ \\
\hline 5 & Resistance & $\mathrm{R}$ & $0,75 \pm 0,05 \Omega$ \\
\hline
\end{tabular}

The LM35 temperature sensor component functions to measure the temperature produced by the Peltier component so that it can be analyzed in this study. This LM35 temperature sensor component is placed inside the research tool box so that it can read the effectiveness of the temperature reading. Figure 6 shows the temperature sensor components used.

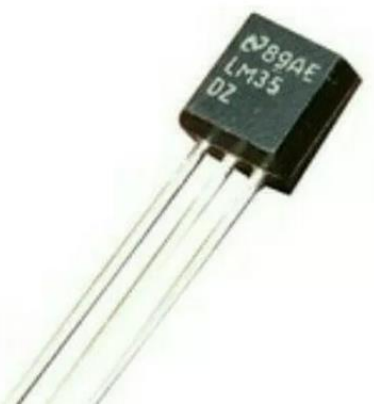

Figure 6. LM35 temperature sensor

Based on Figure 6 shows the LM35 temperature sensor components used in the research The LM35 temperature sensor has three pins, namely the Vcc pin which is connected to the Arduino voltage source, the Vout pin connected to the Arduino pin, and the ground pin which is connected to a ground source on the Arduino.

\section{B. Hardware Design}

The hardware design carried out in this study can be divided into two box sizes. This cooling and heating device has dimensions of $40 \mathrm{~cm}$ long, $20 \mathrm{~cm}$ wide and 32 $\mathrm{cm}$ high. The box used is a box made of aluminium with the outside coated with Styrofoam and plywood. Styrofoam is used because besides being affordable it can also maintain the temperature in the box. The design of the tool can be seen in Figure 7. 


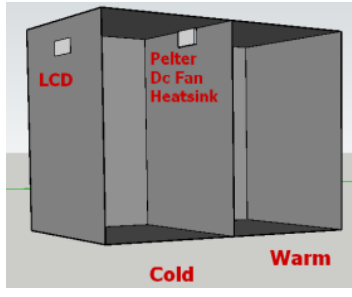

(a)

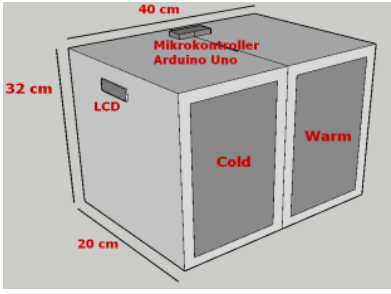

(b)
Figure 7. Display of cooler and warmer (a) Inside view (b) Outside view

The cooling and heating device in the form of a box is divided into two parts, namely cold and warm parts. The cooling and heating systems are placed in the middle of the box with the aim of using both side properties of the Peltier simultaneously and knowing the resulting temperature effect. The application of the Peltier element must simultaneously use the heatsink component as heat absorption. Peltier cannot be used without a heatsink because it causes damage to the Peltier component.

The design of this cooling and heating device consists of several constituent components. These components include a Peltier thermoelectric, DC fan, Arduino Uno, IR receiver, IR remote, 2 channel relay, breadboard, LM35 temperature sensor, and 16x2 LCD. These components are assembled to be connected into one unit and the component layout is formed so that it is easy to operate and maintain. Figure 7 is the initial design of the tool before it is made.

Based on Figure 7, it can be seen that the initial design of the cooling and heating device before being made. In this initial design, the components that will be used can be identified. The initial design shows the position of the $16 \times 2$ LCD which is placed on the side of the cooler, the position of the Arduino Uno microcontroller component is placed on the upper end between the cooler and warmer, and the position of the power supply component which is placed on the back of the cooler and warmer. Based on the final result, the tool making has several differences in the position of the components used. The final result design of the tool that has been made can be seen in Figure 8.

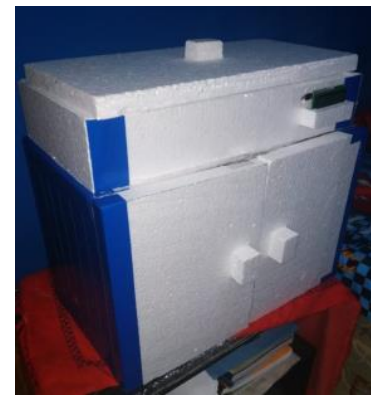

(a)

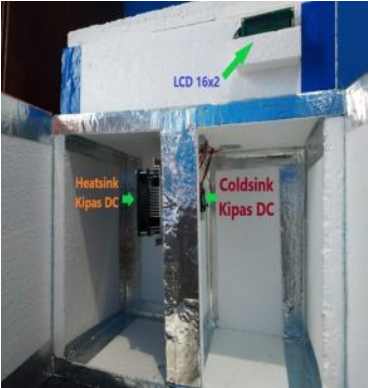

(b)
Figure 8. The final design of the tool after it has been made (a) Outside view (b) Inside view

In the final result of the design of the tool, it can be seen that there are differences in the position of the components used with the initial design that was previously made. The final result of the design of the tool shows the position of the 16x2 LCD component placed on the top of the box and facing the front so that it is expected that the temperature reading is more effective when compared to the initial design which has a $16 \times 2$ LCD position on the side of the box. The position of the Arduino Uno microcontroller component remains at the top of the contact followed by the components connected to the Arduino Uno microcontroller, namely the breadboard, 2 channel relay and IR receiver which is also placed at the top of the cooler and warmer box. The position of the power supply is placed at the top of the cooler and warmer which was previously on the back of the box with the aim of facilitating wiring with the Arduino Uno and Peltier microcontrollers so as to save on cable usage. The position of the power supply is also placed at the top so that it can add to the aesthetics of the device that shows the tool as one unit and not separated between its components.

\section{RESULTS AND DISCUSSION}

Testing the overall design of the tool includes testing the components working simultaneously as one system, testing the temperature readings generated by the sensor, and testing the temperature display that reads on a $16 \times 2$ LCD.

\section{A. Cold Side Test of Two Peltiers}

This test was carried out with three experiments, namely testing the cold side of two Peltier without load, testing the cold side of two Peltier with a load without ice cubes, and testing the cold side of two Peltier with loads and ice cubes to measure the cold temperature produced by two cold sides Peltier by LM35 temperature sensor. The loads used are one $300 \mathrm{ml}$ drink bottle, one $220 \mathrm{ml}$ glass drink, and one ice cube with a size of $18 \mathrm{~cm} \mathrm{x} 12 \mathrm{~cm}$ with a thickness of $3 \mathrm{~cm}$. The results of measurements taken can be written in full in Table 3 .

Table 3. Results of Cold Temperature Measurement of Two Peltier

\begin{tabular}{cccc}
\hline \multirow{2}{*}{$\begin{array}{c}\text { Time } \\
\text { minutes) }\end{array}$} & \multicolumn{3}{c}{ Temperature $\left({ }^{\circ} \mathrm{C}\right)$} \\
\cline { 2 - 4 } & $\begin{array}{c}\text { Without } \\
\text { Loads }\end{array}$ & $\begin{array}{c}\text { With Loads } \\
\text { Without Ice Cubes }\end{array}$ & $\begin{array}{c}\text { With Loads } \\
\text { and Ice Cubes }\end{array}$ \\
\hline 4 & 31.6 & 31.9 & 31.0 \\
\hline 8 & 31.0 & 31.0 & 28.6 \\
\hline 12 & 30.2 & 29.3 & 27.0 \\
\hline 16 & 29.7 & 28.0 & 25.6 \\
\hline 20 & 28.8 & 27.0 & 23.7 \\
\hline 24 & 27.3 & 26.0 & 22.0 \\
\hline 28 & 25.8 & 25.1 & 20.7 \\
\hline 32 & 24.0 & 24.2 & 19.5 \\
\hline 36 & 22.8 & 23.1 & 18.6 \\
\hline 40 & 21.3 & 22.2 & 17.5 \\
\hline
\end{tabular}

The test is carried out in stages over 40 minutes with a span of four minutes the measured temperature will be recorded. The results of temperature measurement against time can be seen in more detail in Figure 9 which shows a graph of the cold temperature measurement results of two peltiers. 


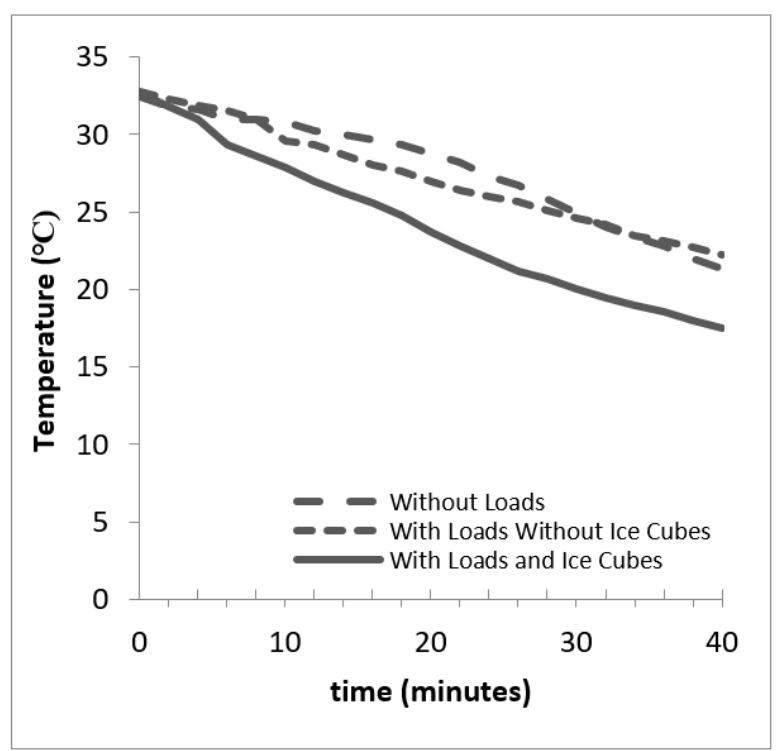

Figure 9. Cold Temperature Change of Two Peltiers against Time

Based on this figure, it is known that the relationship between the cold temperature of the two Peltiers with time is that the longer the two Peltiers are active, the resulting temperature decreases. The lowest temperature produced was the experiment using two Peltiers with loads and ice cubes which produced a temperature of $17.5^{\circ} \mathrm{C}$.

\section{B. Cold Side Test of One Peltier}

This test was carried out with three experiments, namely testing the cold side of one Peltier without load, testing the cold side of one Peltier with a load without ice cubes, and testing the cold side of one Peltier with load and ice cubes to measure the cold temperature produced by one cold side Peltier by LM35 temperature sensor. The loads used are one $300 \mathrm{ml}$ drink bottle, one $220 \mathrm{ml}$ glass drink, and one ice cube with a size of $18 \mathrm{~cm} \mathrm{x} 12 \mathrm{~cm}$ with a thickness of $3 \mathrm{~cm}$. The results of measurements taken can be written in full in Table 4.

Table 4. Results of Cold Temperature Measurement of One Peltier

\begin{tabular}{cccc}
\hline \multirow{2}{*}{$\begin{array}{c}\text { Time } \\
\text { (minutes) }\end{array}$} & \multicolumn{3}{c}{ Temperature $\left({ }^{\circ} \mathrm{C}\right)$} \\
\cline { 2 - 4 } & $\begin{array}{c}\text { Without } \\
\text { Loads }\end{array}$ & $\begin{array}{c}\text { With Loads } \\
\text { Without Ice Cubes }\end{array}$ & $\begin{array}{c}\text { With Loads } \\
\text { and Ice Cubes }\end{array}$ \\
\hline 4 & 32.7 & 33.4 & 33.0 \\
\hline 8 & 32.3 & 32.9 & 32.1 \\
\hline 12 & 31.5 & 32.5 & 31.3 \\
\hline 16 & 31.1 & 32.0 & 30.2 \\
\hline 20 & 30.2 & 31.4 & 29.4 \\
\hline 24 & 29.6 & 30.8 & 28.3 \\
\hline 28 & 29.0 & 30.2 & 27.6 \\
\hline 32 & 28.5 & 29.7 & 27.0 \\
\hline 36 & 28.0 & 29.2 & 26.1 \\
\hline 40 & 27.3 & 28.2 & 25.2 \\
\hline
\end{tabular}

The test is carried out in stages over 40 minutes with a span of four minutes the measured temperature will be recorded. The results of temperature measurement against time can be seen in more detail in Figure 10 which shows a graph of the cold temperature measurement results of one Peltier.

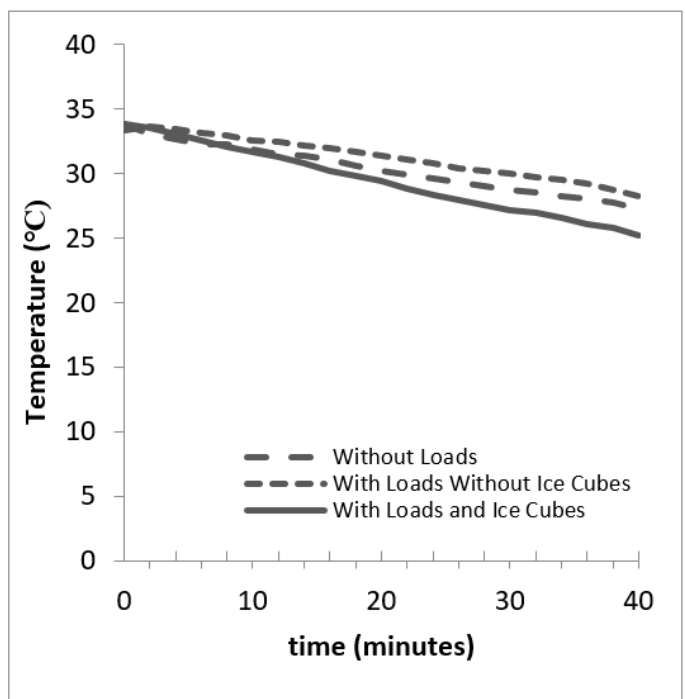

Figure 10. Cold Temperature Change of One Peltier against Time

Based on this figure, it is known that the relationship between the cold temperature of one Peltier with time is that the longer one Peltier is active, the resulting temperature decreases. The lowest temperature produced was the experiment using one Peltier with loads and ice cubes which produced a temperature of $25,2^{\circ} \mathrm{C}$.

\section{Hot Side Test of Two Peltiers}

This test was carried out with two experiments, namely testing the hot side of two Peltiers without loads and testing the hot side of two Peltiers with loads. This test is carried out with the aim of measuring the heat temperature generated by the two hot sides of the Peltier by the LM35 temperature sensor. The loads used are one $300 \mathrm{ml}$ drink bottle and one $220 \mathrm{ml}$ glass drink. The results of measurements taken can be written in full in Table 5 .

Table 5. Results of Hot Temperature Measurement of Two Peltiers

\begin{tabular}{ccc}
\hline \multirow{2}{*}{$\begin{array}{c}\text { Time } \\
\text { (minutes) }\end{array}$} & \multicolumn{2}{c}{ Temperature $\left({ }^{\circ} \mathrm{C}\right)$} \\
\cline { 2 - 3 } & Without Loads & With Loads \\
\hline 4 & 47.3 & 40.4 \\
\hline 8 & 54.5 & 51.7 \\
\hline 12 & 62.3 & 54.5 \\
\hline 16 & 69.2 & 58.9 \\
\hline 20 & 71.0 & 61.6 \\
\hline 24 & 73.3 & 63.6 \\
\hline 28 & 75.8 & 65.3 \\
\hline 32 & 77.2 & 66.5 \\
\hline 36 & 78.4 & 67.9 \\
\hline 40 & 80.2 & 70.7 \\
\hline
\end{tabular}


The test is carried out in stages over 40 minutes with a span of four minutes the measured temperature will be recorded. The results of temperature measurement against time can be seen in more detail in Figure 11 which shows a graph of the hot temperature measurement results of two Peltiers.

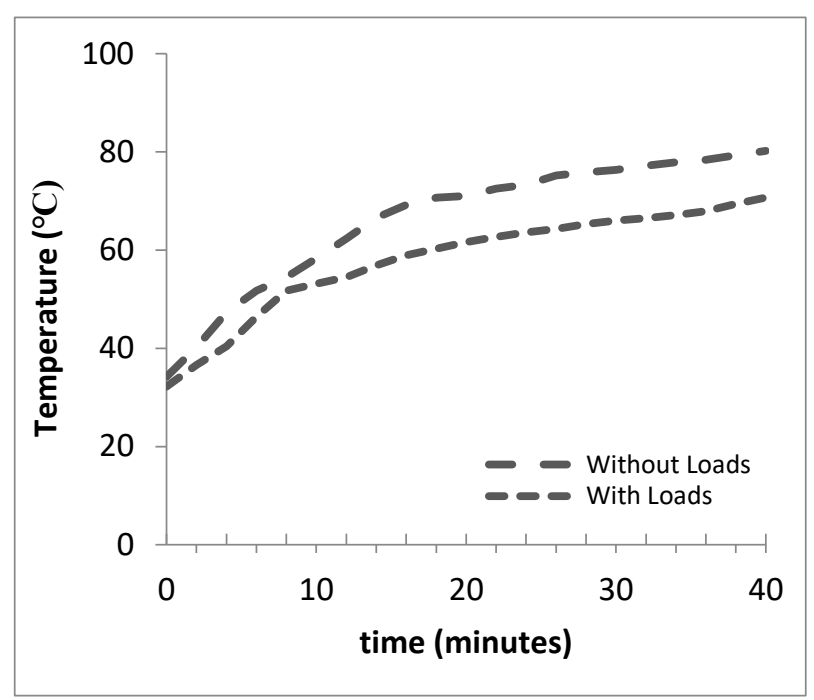

Figure 11. Hot Temperature Change of Two Peltiers against Time

Based on this figure, it is known that the relationship between the heat temperature of the two Peltiers with time is that the longer the two Peltiers are active, the resulting temperature increases. The highest temperature produced was the experiment using two Peltiers without loads which produced a temperature of $80,2{ }^{\circ} \mathrm{C}$.

\section{Hot Side Test of One Peltier}

This test was carried out with two experiments, namely testing the hot side of one Peltier without loads and testing the hot side of one Peltier with loads. This test is carried out with the aim of measuring the heat temperature generated by the one hot side of the Peltier by the LM35 temperature sensor. The loads used are one $300 \mathrm{ml}$ drink bottle and one $220 \mathrm{ml}$ glass drink. The results of measurements taken can be written in full in Table 6 .

Table 6. Results of Hot Temperature Measurement of One Peltier

\begin{tabular}{ccc}
\hline \multirow{2}{*}{$\begin{array}{c}\text { Time } \\
\text { (minutes) }\end{array}$} & \multicolumn{2}{c}{ Temperature $\left({ }^{\circ} \mathrm{C}\right)$} \\
\cline { 2 - 3 } & Without Loads & With Loads \\
\hline 4 & 36.4 & 37.1 \\
\hline 8 & 40.1 & 39.3 \\
\hline 12 & 46.3 & 41.9 \\
\hline 16 & 49.1 & 44.0 \\
\hline 20 & 52.2 & 45.1 \\
\hline 24 & 54.8 & 46.0 \\
\hline 28 & 56.5 & 47.0 \\
\hline 32 & 58.1 & 48.3 \\
\hline 36 & 59.4 & 49.2 \\
\hline 40 & 60.5 & 51.2 \\
\hline
\end{tabular}

The results of temperature measurement against time can be seen in more detail in Figure 12 which shows a graph of the hot temperature measurement results of one Peltier.

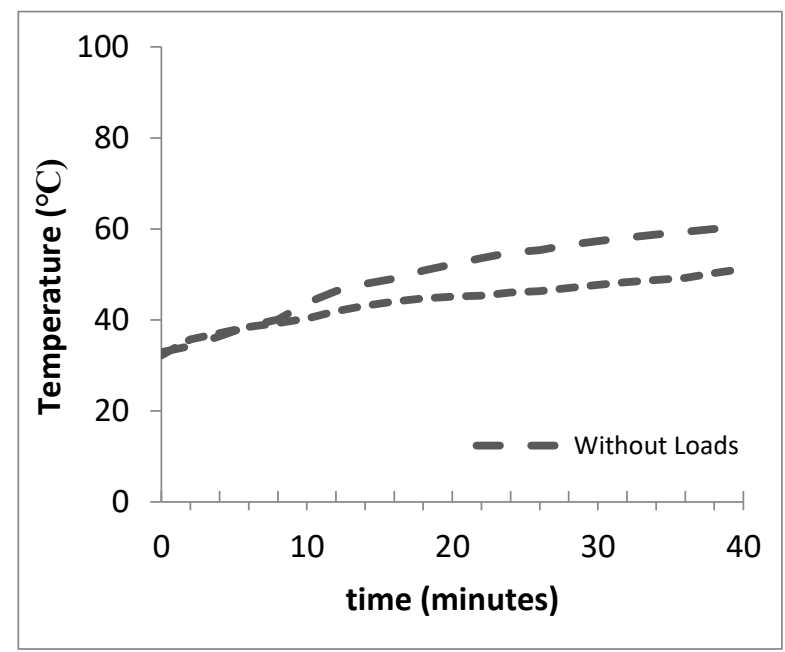

Figure 12. Hot Temperature Change of One Peltier against Time

Based on this figure, it is known that the relationship between the heat temperature of the one Peltier with time is that the longer the one Peltier are active, the resulting temperature increases. The highest temperature produced was the experiment using two Peltiers without loads which produced a temperature of $60,5{ }^{\circ} \mathrm{C}$. The test is carried out in stages over 40 minutes with a span of four minutes the measured temperature will be recorded.

\section{CONCLUSION}

Based on the research, it can be seen that the use of a Peltier thermoelectric as a coolant is still not as effective as using a traditional cooler because the cooling results have not been able to reach freezing point. The additional load in the form of one $300 \mathrm{ml}$ drink bottle and one 220 $\mathrm{ml}$ glass drink makes the resulting cooling process even longer by looking at the time difference needed to reach a certain temperature when compared to the no-load tool testing. The use of ice cubes and two Peltiers in the cooler produces the lowest temperature of $17.5^{\circ} \mathrm{C}$ which causes the box to get colder because the cold temperature produced by the Peltier mixes with the cold temperature of the ice cubes. Based on the research, it is known that the cooling and heating patterns are directly proportional. The colder the resulting temperature, the warmer one side will be with a maximum temperature difference of $70{ }^{\circ} \mathrm{C}$.

\section{REFERENCES}

[1] Willfried, Jones, Fransisco Stoeker. Alih Bahasa Supratman Hara. Refrigerasi dan Pengkondisian Udara. Erlangga, 1992.

[2] Althouse Andrew, Turnquist Carl, Bracciano Alfred. Pendingin dan Pendingin Udara Modern: South Holland Illions The Good Heard Willcox Company Inc, 1992 
[3] Kai, Wang.. Review Sistem Pendinginan Loop Sekunder. International Journal of Refrigeration, vol. 33, no. 2, pp. 212-234, 2010

[4] Selviana, Windy. Analisa Kinerja Kotak Pendingin dan Penghangat Menggunakan Modul Termoelektrik TEC12706. Bandar Lampung : Universitas Lampung, 2017

[5] Gandi, Frima. Perancangan Sistem Pendingin Air Menggunakan Elemen Peltier Berbasis Mikrokontroler ATmega 8535. Andalas University Physics Journal, vol. 5, no.1, pp. 35-41, 2016

[6] Riffat, Saffa, Ma Xiaoli. Thermoelectrics: a review of present and potential applications. International Journal of Applied Thermal Engineering, vol. 23, no. 8, pp. 913935, 2003

[7] Purwiyanti, Sri, F.X Arinto Setyawan. Aplikasi Efek Peltier Sebagai Kotak Penghangat dan Pendingin Berbasis Mikroprosessor Arduino Uno. Journal of Electrical Engineering and Technology Electrician, vol. 11, no. 3, pp. 92-125, 2017.

[8] Sulistiyanto, Nanang. Pemodelan Sistem Pendingin Termoelektrik. Journal of Electrics, Electronics, Communications, Controls, Informatics, System Universitas Brawijaya, vol. 8, no. 1, pp. 67-72, 2014.

[9] Min, Gao, D.M. Rowe. Improved Model for Calculating The Coefficient of Performance of Peltier Modules. International Journal of Thermoelectric Materials and Devices, vol. 41, no. 2, pp. 163-171, 1999.

[10] Poetro, J.Eko. Konservasi Energi Pada BTS (Base Transceiverstation) Menggunakan Sistem Pendingin Arus Searah (DC Cooler). Jurnal Teknik Mesin Universitas Negeri Malang, vol. 20, no. 2, pp. 32-43, 2011.

[11] Components101.com. 2018. Arduino Uno Technical Specifications. (Accessed on 25 November 2020). https://components101.com/microcontrollers/arduinouno.

[12] Datasheetpdf.com. 2014. TEC1-12715 Datasheet. (Accessed on 25 November 2020). https://data sheets pdf.com/pdf/869806/HB/TEC1-12715/1. 